\title{
CONCEPÇÕES PSIQUIÁTRICAS SOBRE O ESPIRITISMO NA PRIMEIRA METADE DO SÉCULO XX
}

Roberta Scoton*

Resumo: Neste artigo, analisamos o discurso médico e psiquiátrico sobre as religiões mediúnicas, na primeira metade do século XX. Enfocamos o caso de Juiz de Fora (MG), comparando e inter-relacionando com o que ocorria no restante do país no que se refere ao assunto. Observamos que esses estudos sobre o espiritismo se inseriam em um contexto mais amplo de institucionalização e luta pela hegemonia da medicina acadêmica no Brasil.

Palavras-chave: Espiritismo. Medicina. Psiquiatria. Juiz de Fora-MG.

Abstract: In this paper, we analyze the medical and psychiatric speech about mediumistic religions on the first half of $20^{\text {th }}$ century. We emphasize the case of Juiz de Fora, MG (Brazil), comparing and intertwining with what was occurring throughout the country in reference to it, observing that these studies about spiritism were inserted in a bigger context of institutionalization and fight for hegemony of Brazilian academic medicine.

Keywords: Spiritism. Medicine. Psychiatry. Juiz de Fora-MG.

A aceitação popular [do espiritismo], tal como vinha ocorrendo na Europa, incentivava a investida dos detratores. Qualquer argumento seria bom. O mais comum, porém, de maior impacto e mais invocado, repetido até a exaustão, garantia que o espiritismo era uma fábrica de loucura. Essa associação de espiritismo e loucura, na sociedade brasileira de então [final do século XIX], carecia de fundamento. Era mero eco do que se prolongava na Europa. O fenômeno só começaria a ocorrer, aqui, nas décadas seguintes, quando a imensa falange de desadaptados, social e psicologicamente, começou a acorrer aos centros, em busca de consolo mais eficaz que a simples promessa de arder eternamente. (MACHADO, 1996, p. 115)

\footnotetext{
${ }^{*}$ Universidade Federal de Juiz de Fora
} 
O trecho acima nos mostra, como os espíritas foram sendo relacionados com a loucura, do final do século XIX ao início do século XX. Coloca que, de um argumento sem muita base científica, ele foi sendo paulatinamente respaldado na ciência e medicina acadêmica do início do século XX. Neste artigo, analisaremos justamente esta segunda fase, em que o espiritismo passa a ser visto como uma "fábrica de loucura". Enfocaremos o caso de Juiz de Fora (MG), comparando e inter-relacionando com o que ocorria no restante do país, no que se refere ao assunto. Selecionamos todas as atas da SMCJF (Sociedade de Medicina e Cirurgia de Juiz de Fora) com assuntos referentes a três itens: charlatanismo, exercício ilegal da medicina e espiritismo.

Dividimos este texto em duas partes. Na primeira, colocamos as discussões referentes ao exercício ilegal da medicina e charlatanismo de maneira geral, incluindo apenas um caso importante acerca do espiritismo que se deu em 1912, porque nele o espiritismo aparecia como um entre outros charlatanismos. Além disso, foi uma discussão importante porque teve repercussão na imprensa local e levou a reação pelos espíritas kardecistas da cidade. Já na segunda parte, trabalharemos especificamente sobre as ideias psiquiátricas sobre o espiritismo, apontando também o posicionamento dos médicos da cidade de Juiz de Fora.

No período em que abrange nossa análise, ocorre 0 auge da industrialização da cidade, que se deu principalmente através da inversão de capitais do café para a indústria. (PIRES, 1996, p. 1) Até a década de 1920, a elite juizforana se esforça para manter uma imagem de lócusdo progresso e da civilidade, o que se reforçou pelas designações de "Princesa", "Atenas"e "Manchester Mineira", e foi concretizado através das indústrias, da imigração, da fundação de Academias e Sociedades científicas e literárias, da construção de teatros e cinemas. Estes elementos "refletem a vontade de forjar uma nova imagem para a cidade, fugindo da tradição escravista (CHRISTO, 1994, p. 379) identificada a cultura colonial mineira.

A SMCJF, criada em 20 de outubro de 1889, pelos médicos João Nogueira Penido e Romualdo César Monteiro de Miranda, era uma instituição na cidade que se preocupava com o problema da Higiene e saneamento, questões as quais se inseriam em um processo mais amplo de urbanização pelo qual a cidade passava. ${ }^{1}$

${ }^{1}$ Ata da SMCJF, de 09/10/1889. In: Boletim da SMCJF, ano 1. 
Desde sua fundação, esta instituição buscou se vincular ao poder público municipal, através da intervenção em vários problemas da administração pública. A SMCJF, a partir das primeiras eleições provinciais após a Proclamação da República, passa a ter vários de seus membros com assento na Câmara: os médicos passam a elaborar pareceres, opinar e agir mais diretamente sobre os principais projetos do município (LANA, 2005). Em nome da salubridade pública e de medidas profiláticas, os membros da SMCJF buscaram exercer um forte poder político sobre os indivíduos. Segundo M. Christo (1994), o ideal de higiene pública remetia diretamente ao "projeto de modernização" da cidade, na medida em que se tentava "não só controlar a mente e os braços dos trabalhadores, mas igualmente sua saúde" (CHRISTO, 1994, p. 124).

Em 14/05/1892, através da Resolução da Câmara de Vereadores, é criada a organização do serviço de higiene, incumbida:

[d]o estudo de todas as questões relativas a higiene publica do município (...), o saneamento das localidades e habitações (...), adoção de meios tendentes a previnir, combater ou attenuar as moléstias endêmicas, epidêmicas e transmissíveis ao homem e aos animais, (...) a inspecção sanitária das escolas, fabricas e officinas, hospitaes, hospícios, prisões, estabelecimentos de caridade e beneficência, quartéis, asylos e quaesquer habitações collectivas publicas e particulares (...)" e - importante para este trabalho - "a fiscalização do exercício ilegal da medicina e da pharmacia. ${ }^{2}$

Além disso, vale destacar que eram os próprios acadêmicos que fiscalizavam o exercício da medicina e farmácia: "A nomeação do delegado de hygiene recahirá sempre em profissionaes, médicos e pharmaceuticos". ${ }^{3}$ Portanto, através de duas frentes, o exercício ilegal da medicina era combatido, seja através da SMCJF ou da Inspetoria de Higiene.

\footnotetext{
${ }^{2}$ Resolução da Câmara de Juiz de Fora, 14/05/1892, p. 11-12. Arquivo Histórico da Prefeitura de Juiz de Fora.

${ }^{3}$ Idem. p. 12.
} 


\section{O EXERCÍCIO ILEGAL DA MEDICINA E O CHARLATANISMO}

O Código Penal de 11.10.1890 - em seus artigos 156, 157 e 158 - concretiza em forma de lei as aspirações da medicina acadêmica no Brasil durante o século XIX. Definem a criminalização de se "praticar o espiritismo, a magia e seus sortilégios (...) para despertar sentimentos de ódio ou amor, incultar cura de moléstias curáveis ou incuráveis, enfim, para fascinar e subjugar a credulidade pública" (art. 157). Também se proíbe "exercer a medicina em qualquer de seus ramos, a arte dentar ou a farmácia; praticar a homeopatia, a dosimetria, o hipnotismo ou magnetismo animal, sem estar habilitado segundo as leis e regulamentos" (art. 156). Além disso, ocorre a penalização de se "ministrar (...), como meio curativo, (...) substâncias de qualquer dos reinos da natureza, fazendo ou exercendo, assim, o ofício do denominado curandeiro" (art. 158) (GIUMBELLI, 1997, p. 79-80). A partir destes artigos, observamos a condenação do exercício ilegal da medicina e a criminalização das práticas do espiritismo, da magia, do curandeirismo, através de dois argumentos principais: por um lado, são considerados crimes à credulidade pública, e, por outro, possíveis desencadeadores de doenças mentais.

A primeira referência ao charlatanismo em Juiz de Fora observada em atas médicas é de maio de 1904. Nesta ata o presidente da SMCJF da época, o Dr. Eduardo de Menezes apresenta aos sócios o cirurgião-dentista Antonio Dias de Carvalho e convida esse "novo consórcio, para que, estudando e tomando interesse pelas questões científicas, levante os créditos de sua classe, cuja arte está tão barateada pela invasão de charlatões e de exploradores audaciosos, sem preparos nem conhecimentos". ${ }^{4}$

Observa-se nesta ata uma reafirmação da função corporativa da Sociedade e de que seus membros deveriam se unir para o combate aos charlatães e aos exploradores da profissão médica, impedindo o monopólio acadêmico sobre a arte de curar.

Já em março de 1907, o Dr. José Dutra denuncia à sociedade um acaso de infração da lei sanitária municipal. Segundo o médico, depois de ter sido chamado para tratar de uma criança com diphteria, observou que havia um

\footnotetext{
${ }^{4}$ Boletim da SMCJF - maio/1904.
} 
novo receituário ministrado por um farmacêutico da cidade. Portanto, comunica o ocorrido à SMCJF e também ao sócio José Nava, presente no momento, e que é a autoridade sanitária do município. Eduardo de Menezes compreende que isso não é um caso somente de exercício ilegal da medicina, mas também de um atentado contra a saúde pública. ${ }^{5}$

Uma discussão importante que extrapolou os limites da SMCJF e que revela de forma importante a relação entre os kardecistas e a medicina acadêmica, no âmbito das discussões e disputas sobre o monopólio dos tratamentos, curas e explicações das doenças, ocorreu em 1912. Podemos observar a preocupação dos médicos locais quanto à questão do exercício ilegal da medicina pelos espíritas através dos jornais, como é o caso da matéria intitulada Protesto dos Médicos, no jornal $O$ Pharol, de 06/02/1912, em que há a transcrição de uma carta da classe médica de Juiz de Fora aos de São Paulo, apoiando o protesto destes em relação ao projeto de lei de Reforma do Ensino, Rivadavia Corrêa, que propunha entre outras coisas, o exercício livre da medicina. Na carta, os médicos juizforanos declaram apoiar os médicos paulistas, os quais defendem o exercício da medicina como direito exclusivo da classe diplomada e criticavam a atitude dos espíritas que se envolviam em questões de cura. Os médicos referiam-se ao espiritismo como um perigo à saúde pública, na medida em que as pessoas estariam a se "entregar os vitaes interesses da saúde pública a indivíduos ignorantes e gananciosos, invocando a proteção de uma seita”. Já no dia seguinte, o Centro Espírita União, Humildade e Caridade envia uma carta-resposta que foi publicada no mesmo jornal, com o título O protesto da Classe médica. O espiritismo não explora. Neste texto, os espíritas defendem a sua doutrina e afirmam: "Distribuindo o Centro diariamente, aos pobres e aos crentes, as suas receitas homeopáticas, recebidas mediunicamente, não atenta o mesmo nem a liberdade individual nem aos interesses da illustre corporação que ora levanta um enérgico protesto contra o Espiritismo (...)." 6

Concluem a carta sugerindo aos médicos que visitem os centros espíritas para verem as "sessões curativas do Centro". No dia posterior, outra carta-resposta ao protesto dos médicos é enviada, com o título O espiritismo não explora.

${ }^{5}$ Boletim da SMCJF - mar/1907.

${ }^{6}$ Jornal Pharol, 07/02/1912. 
Outra carta. Neste texto, o autor, um espírita que não se identifica, cita o caso de um médium que foi absolvido depois de ser acusado pelo Ministério Público de Portugal por "ter procurado curar doentes sem título legítimo para exercer a profissão de médico, usando supostos segredos". O autor da carta transcreve alguns fragmentos do Acórdão de onde coletou estes dados, que foi o Acórdão da Relação do Porto de Portugal. Nele afirma-se que

não commeteu delicto algum o arguido, procurando, (...) curar gratuitamente (...) pelo magnetismo, pelo hypnotismo ou pela simples imposição de mãos quem o aborda; por que não se arroga a profissão de médico, que é remunerada. Que philantropicamente se põe a disposição da humanidade para alliviar os seus males; que, em vez de receber qualquer remuneração por seus serviços, muitas vezes é o primeiro a socorrer e dar esmolas aos consulentes necessitados $(\ldots)^{7}$

Como podemos perceber, o espiritismo era uma dentre outras formas de medicinas "paralelas" à medicina acadêmica que se oficializava. O Kardecismo se defendia das acusações de exercício ilegal da medicina afirmando não cobrarem pelas curas, fazendo-as por caridade. Isso também era uma forma de se distinguir das outras práticas e religiões mediúnicas, como o "baixo-espiritismo", a umbanda, o candomblé etc.

Em 1919, uma sessão extraordinária é convocada a pedido do Dr. Delegado de Higiene da Zona da Mata para tratar de assuntos acerca do exercício ilegal da medicina, farmácia e odontologia. ${ }^{8}$ Através desta ata e das posteriores, obtivemos informações acerca do funcionamento da política sanitária do Município e Estado e, principalmente, no que se refere à regulação das profissões ligadas ao cuidado da saúde. Em meio à discussão acerca de como se deveria coibir o exercício ilegal da medicina e o charlatanismo, o Dr. Simão Faria propõe que se restabeleça o cargo de Diretor de Higiene Municipal, o qual deveria se aliar à polícia e às autoridades sanitárias estaduais. Constatamos através desta ata que o delegado de Higiene da Zona da Mata é submetido pelo Diretor de Higiene Estadual na realização

${ }^{7}$ Jornal Pharol, 08/02/1912.
${ }^{8}$ Ata da SMCJF, out/1919.

Debates do NER, Porto Alegre, ANo 10, N. 15, P. 105-128, JAN./Jun. 2009 
de suas tarefas. Porém, o que observa-se na prática é que a fiscalização do exercício ilegal da medicina e a regulação e expedição de licença de funcionamento das farmácias eram feitas de duas maneiras: ou pela Câmara Municipal, atendendo as leis municipais de 1982; ou pela Diretoria de Higiene estadual.

Entre as décadas de 1920 e 1940 encontramos poucas referências ao exercício ilegal da medicina. Um exemplo é de 1928, em que a SMCJF em sua ata enumera suas atividades principais e entre elas destaca “(...) desenvolvimentos (...) nos serviços de propaganda e educação sanitária, Inspetoria de fiscalização do exercício ilegal da medicina e da farmácia (...) etc." " Outra referência é de 1938, em que o dr. Paulo Japiassú levanta a discussão sobre o charlatanismo na cidade, o qual segundo ele, toma aspectos "ameaçadores" à vida do doente e também à reputação da classe médica local. ${ }^{10}$ Ainda em 1939, a SMCJF pede à polícia da cidade que exerça maior vigilância e fiscalização a fim de evitar exploração do trabalho médico. ${ }^{11}$

\section{ESPIRITISMO E LOUCURA}

No campo da psiquiatria, o espiritismo foi um assunto bastante recorrente, apontado como causa de alienação mental. Analisaremos as principais ideias de médicos e psiquiatras que abordaram o tema das religiões mediúnicas.

O primeiro a escrever sobre o espiritismo foi Francisco Fajardo, em seu Tratado de Hipnotismo, de 1896. O autor é filiado à psicologia fisiológica francesa, que propunha um desligamento entre a psicologia e a filosofia e sua aproximação com a fisiologia, disciplina médica. Opõe-se, portanto, à psicologia espiritualista. Seus principais objetos de estudo são as mudanças de comportamentos, o sonambulismo, as amnésias, o efeito de sugestionamentos e o comportamento irracional de multidões. (GIUMBELLI, 1997, p. 151)

No Rio de Janeiro, o grande divulgador da hipnose foi o médico Érico Coelho, professor da Faculdade de Medicina (1887) e nos anos seguintes o

\footnotetext{
${ }^{9}$ Ata da SMCJF, jul/1928.

${ }^{10}$ Ata da SMCJF, jan/1938.

${ }^{11}$ Boletim da SMCJF, fev/1938.
} 
assunto ganha prestígio. Neste contexto, surgiram as primeiras formulações mais específicas acerca dos fenômenos relacionados ao espiritismo. Fajardo parte do princípio de que "todo mundo é invariavelmente sujeito a influências hipnogênicas”, sendo importante a demonstração das potencialidades terapêuticas da sugestão, de suas aplicações com psicoterapia ou medicina sugestiva.

F. Fajardo dedica um capítulo de seu livro ao espiritismo, explicando seus fenômenos pela doutrina das variações e alterações da consciência. Como exemplo, afirma que a psicografia seria produto de automatismo cerebral e de sugestões e não simulações: seria um estado alucinatório, em que a ilusão dos sentidos convence o indivíduo de não ter sido ele o autor da mensagem escrita.

O espiritismo é mencionado em outro capítulo, Hipnotismo e Criminalidade, em que afirma que as técnicas do hipnotismo e da sugestão, caindo em mãos erradas, poderiam causar grandes danos à sociedade. Os argumentos de Fajardo se desenvolvem em dois níveis. Por um lado, há uma "fenomenização" do espiritismo em que os fatos a ele relacionados, principalmente a mediunidade, passam a merecer uma consideração específica que os torna objeto de uma psicologia. Por outro lado, apresenta um argumento sociológico, na medida em que contempla os usos e os fins de um "fenômeno", desqualificando o espiritismo, "visto estarem seus grupos orientados por exploradores da boa fé e da propriedade alheias".

Muito importante também é a figura de Nina Rodrigues, tanto em relação à história do pensamento social, quanto pela influência de suas concepções sobre as formulações antropológicas posteriores. Sua atuação cobre não só os campos da medicina, da psicologia ou psiquiatria, mas também do direito e da antropologia.

Este médico utiliza a categoria "sugestão" associada à existência de algum tipo de predisposição, "espécie de 'terreno' sobre o qual um sugestionamento ganha condições de eficácia”. (Idem, p. 158) Tal aspecto se relaciona à sua atenção às desigualdades humanas e a uma ciência da diferença, que relaciona o social ao biológico. Trabalha com o estado de possessão nos candomblés baianos e afirma que tais fenômenos não são farsa ou simulação e que a possessão de santos derivaria de estados de sonambulismo provocado, havendo substituição de personalidade, alucinações e amnésia completa. Sustenta a base patológica das 
manifestações de possessão, ou seja, "para que a 'hipnotização' efetivamente ocorresse e a possessão se desse, deveria haver um 'terreno patológico', localizado na psicologia humana”. (GIUMBELLI, p. 159)

Em A loucura das multidões: uma contribuição para o estudo das loucuras epidêmicas no Brasil(1901), incluído em sua obra Coletividades anormaisencontra-se a demonstração de que suas conclusões sobre as possessões de santo poderiam ser aplicadas à mediunidade dos espíritas. Analisa o caráter patológico que se manifesta nas atitudes de coletividades impulsionadas pelo que denomina 'estado de multidão'. Um dos casos que cita é relacionado às práticas de uma "seita espírita” de Taubaté (SP), envolvendo delírios, sacrifícios, imundícies, torturas, procissões... Essa seita foi vista pelo médico como um exemplo de "epidemia doméstica de loucura”, em que há a "sugestão coletiva”, além de perceber a existência de "predispostos" ou mesmo pessoas com anomalias mentais evidentes entre os membros do grupo.

A antropóloga Simone Guedes, analisando a obra de Nina Rodrigues, Coletividades anormais, afirma que o médico estuda casos de "loucura coletiva" dentro de uma perspectiva denominada por ele de "psicologia coletiva'. Nina estuda um caso de doença relacionada à dificuldade motora e atribui seu caráter epidêmico ao contágio por imitação (um contágio mental). Aponta o estado religioso da população como uma das causas predisponentes a este tipo de contágio. Além disso, afirma que "o fato tem sua explicação racional e científica no mestiçamento”. (GUEDES, 1985, p. 1985)

Franco da Rocha foi diretor do Hospital Juquery, em São Paulo, e um dos seguidores de Nina Rodrigues. Faz observações acerca da internação de frequentadores de práticas espíritas no hospício em que era diretor, tanto em obras, quanto em relatórios (GIUMBELLI, 1997, p. 160-161). Em "Esboço de psiquiatria forense", escrito como guia para médicos e juízes, lembra "os perigos das sessões espíritas" e coloca o espiritismo entre os "fatores desencadeadores" de moléstias mentais em pessoas predispostas ou degeneradas.

Em seu relatório anual, declara que, no Hospício de Alienados de São Paulo, o espiritismo era uma causa crescente de loucura. De acordo com a historiadora Angélica Almeida et al (2005, p. 08), foi no século XX que as conferências, publicações e teses sobre a natureza prejudicial do espiritismo cresceram nas escolas de medicina, radicalizando-se o discurso. 
Giumbelli pergunta-se, sobre quais seriam as implicações das teorizações propostas por hipnólogos e alienistas para o direito em seu tratamento dos casos envolvendo a prática do espiritismo. O autor distingue dois níveis: tanto os alienistas, quanto os hipnólogos acreditavam que "práticas espíritas" poderiam estar envolvidas com lesões psíquicas e danos à propriedade; por outro lado, em relação à responsabilidade do médium, para o hipnólogo era um fenômeno de alteração da consciência e para o alienista, um sintoma de anomalia mental. Porém, os hipnólogos foram aos poucos sendo marginalizados no campo intelectual e institucional da medicina e psiquiatria, por aproximarem-se às práticas e saberes tidos como charlatanescos, inclusive com o espiritismo (GIUMBELLI, 1997, p. 165-166).

Outros expoentes foram Afrânio Peixoto, Oscar Pimentel e Henrique Roxo. O primeiro, na década de 1910, visita sessões de espiritismo e conclui que elas são "um laboratório empírico de sugestão e de histeria, onde o automatismo e a subconsciência tomam o nome de manifestações espíritas". O saber de Afrânio Peixoto é produzido e aplicado no espaço do gabinete médico-legal da polícia (1909) e sua pesquisa constitui-se em torno da definição do crime e do desvio social.

Em 1919, Oscar Pimentel apresentou, na Faculdade de Medicina do Rio de Janeiro, a tese Em torno do espiritismo, na qual defende que o espiritismo é uma crença absurda e primitiva e seus fenômenos, quando não são produto de uma simples fraude, são associados à sugestão, sonambulismo e alucinação. Expõe seus "experimentos" desde 1916 e suas conclusões são "contrárias à verdade dos fenômenos espíritas" (GAMA, 1992, passim). Para ele, a crença no espiritismo era uma reminiscência do passado, "de um estágio menos evoluído da civilização", fruto de uma "crença primitiva”. Possui uma perspectiva evolucionista, e relaciona a crença ao atraso em que vivem os indivíduos. Tal comportamento religioso seria contrário a uma suposta "lei natural de progresso".

O médico ataca de duas maneiras o espiritismo: por um lado, afirma que são práticas fraudulentas e, por outro, que esta crença levaria à doença mental. Identifica o espiritismo como causador de desequilíbrio mental e que, dependendo do estágio, não haveria mais a possibilidade de cura. O kardecismo aparece 
como uma doutrina baseada em misticismos e superstições e diz que o codificador do espiritismo era um "embusteiro". ${ }^{12}$

Explica o fato de o Rio de Janeiro ser palco privilegiado de atuação do espiritismo pela grande aceitação popular. Isto porque a população da cidade seria marcada pela loucura, pelo analfabetismo, alcoolismo, pela sífilis, histeria, epilepsia, pelas doenças venéreas. Todos esses elementos explicariam a rápida difusão do espiritismo. Vale citar a análise do sociólogo Cláudio Gama acerca desta questão:

A crença consistiria por um lado em um sinal e por outro em uma causa de doença mental. Os médiuns e freqüentadores dos centros espíritas eram vistos como sugestionados, charlatães ou alucinados. Os charlatães seriam caso de polícia; os alucinados caso de médico, devendo ser internados em hospícios; quanto aos sugestionados ainda não em estado psíquico grave, O. Pimentel os classificava como predispostos a desenvolver doença mental. (GAMA, 1992, p. 218)

Oscar Pimentel foi aluno de Juliano Moreira, que foi discípulo de Nina Rodrigues. Em termos clínicos, via a crença e os fenômenos espíritas como consequência de sugestão, hipnotismo ou alucinação. O tratamento deveria ser feito por sugestão, não possuindo, entretanto, efeito real de cura. Considerava a sugestão um dos elementos mais importantes para a compreensão do espiritismo, "pois esta consistia em uma causa fundamental do renascimento da superstição, magia, feitiçaria e da antiga medicina sacerdotal.” (Idem, p. 241)

Outro médico importante foi Henrique Roxo, que foi chefe do Instituto de Neuropatologia do Hospital Nacional de Alienados. Ele inclui perguntas sobre a frequência a centros espíritas nos formulários para admissão de pacientes na instituição. Constata que entre 1915 e 1930, 10\% dos pacientes desenvolveram patologias mentais em virtude do contato com "práticas espíritas". Giumbelli (1997, p. 201), considera Henrique Roxo um exemplo do modo como a preocupação com o espiritismo foi capaz de angariar esforços de teorização, práticas de observação e diagnóstico psiquiátrico.

${ }^{12}$ Idem. p. 215-216. 
Entre o final da década de 1910 e meados da década de 1930, anunciava-se o espiritismo como sendo o terceiro fator de alienação mental no Brasil, logo após a sífilis e o alcoolismo. Henrique Roxo acreditava que as afecções mentais relacionadas com o espiritismo representavam uma "entidade clínica" específica pelos seus sintomas e seu mecanismo de atuação. Em um primeiro momento, denominou a afecção causada pelo espiritismo de "delírio episódico dos degenerados" - publicado em artigo com o mesmo nome da afecção, veiculado pelo Brasil-Médico, (XL, v. 1, n. 19, 1926) - e mais tarde de "delírio espírita episódico” (designação a partir de 1930): Para ele, trata-se de “(...) um delírio que se fundamenta em alucinações que surgiram conseqüentemente a um choque emotivo, sendo ele, em geral, pouco duradouro e tendo a capacidade de se repetir com relativa facilidade". (ROXO, 1926, apud:GIUMBELLI, 1997, p. 202).

De acordo com Giumbelli, no ano de 1927, há uma modificação no pensamento médico, o que é demonstrado através do inquérito sobre o espiritismo, promovido pela SMCRJ. Concluem que ele não é apenas nocivo à saúde da população, mas também em relação ao surgimento de anomalias psíquicas em indivíduos sujeitos à sua ação. Neste período, a ideia de que o espiritismo fosse um "fator de doença mental" passa a ser senso comum entre médicos e psiquiatras.

Xavier de Oliveira foi aluno de Juliano Moreira e assistente de H. Roxo no Instituto de Neuropatologia por nove anos. Discordava da ideia de que o espiritismo pudesse dar ensejo a perturbações que se constituíssem em uma entidade clínica com o mesmo estatuto de outras neuroses e psicoses. Ao contrário de H. Roxo, enfatiza a existência de um comprometimento psíquico anterior, a partir do qual se desenvolveria a "espiritopatia", entendida como "síndroma mental de forma delirante, com motivos espíritas, e que se observa enxertada em indivíduos tarados do sistema nervoso, nomeadamente da classe dos histeroesquizóides". (OLIVEIRA, apud: GIUMBELLI, 1997, p. 202)

Afirma que, em 12 anos, 9,4\% dos pacientes hospitalizados na clínica psiquiátrica da Universidade do Rio de Janeiro, "sofrem psicoses causadas somente e exclusivamente pelo espiritismo". Além disso, o espiritismo seria perigoso por induzir ao crime e por ser causa de charlatanismo. As religiões mediúnicas eram consideradas um mal social, a maior causa da "alienação mental de feição puramente religiosa” e deviam ser tratadas como uma questão de higiene pública: 
"o espiritismo é considerado como uma doença contagiosa, como uma epidemia, ou como um vício”. (GAMA, 1992, p. 219)

Procura explicar o porquê da ampla difusão indistinta do espiritismo, já que está presente em países menos evoluídos e também nos países civilizados, avançados e prósperos. O espiritismo seria uma doença que se alastra, marcando uma época de "ressurreição das velhas crenças da humanidade". Denuncia a prática de curandeirismo, afirma que há estreitas relações entre médiuns e homeopatas e "reclama da concorrência de tais tratamentos frente à medicina".

Também para Xavier de Oliveira, como para Oscar Pimentel, o espiritismo era uma "reminiscência do passado da humanidade em evolução contínua". E o médico atribuía o fenômeno à ignorância do povo, sendo esta ignorância resultado da carência de instrução, baixa capacidade intelectual e inferioridade mental.

Utiliza a categoria espiritismo para agrupar indistintamente diversas vertentes de religiões mediúnicas. Segundo o médico, que diz ter frequentado vários centros, a busca do espiritismo - em seus variados matizes - termina invariavelmente nos manicômios.

Na mesma linha de outros estudos médicos sobre o espiritismo, Xavier de Oliveira descreve alguns casos com o objetivo de caracterizá-los como "verdadeira calamidade pública”, associando-os ao uso de narcóticos, exploração, curas mentirosas, falsos milagres, falta de higiene, loucura, depravação sexual, violência e crime. O catolicismo é tomado como a religiosidade natural, enquanto o espiritismo, a "mandiga, candomblé, macumba e cangerê" seriam "velha feitiçaria" e disfarces “(...) de uma só e única entidade mórbida, a clássica histeria”.

Acusa o espiritismo de dar gastos ao Estado, na medida em que geraria muitos loucos a serem tratados nas instituições psiquiátricas públicas. Acusa-o também de fazer fraudes e ilusões para explorar os adeptos. Porém, profetiza "que essa epidemia de loucura religiosa terá fim com a evolução e o refinamento do 'pensamento coletivo e da cultura social'." (Idem) Além disso, acredita que com o aumento da qualidade de educação nas escolas e nas famílias, o espiritismo terá fim. Propõe que se queimem todos os livros espíritas, o fechamento dos centros e a instauração do catolicismo como religião obrigatória do país.

Para se referir à doença “causada pelo espiritismo”, usava a expressão “espiritopatia”. Ela seria um sintoma de histeria, que apareceria em "indivíduos de 
constituição mitopática', ou seja, naqueles que acreditassem em 'fenômenos místicos'. Tais indivíduos são definidos como de "fácil sugestionabilidade, com automatismo mental evidente, nos quais o complexo sexual se eleva até a angústia que explode na doença”. Como os outros médicos que estudavam o espiritismo, Xavier de Oliveira diz que as suas conclusões partem de estudos baseados em "observações minuciosas e experimentos científicos".

Em relação ao seu estudo acerca de 'doenças mentais geradas pelo espiritismo', classifica três tipos de espíritas:

a) médiuns falantes ou mitopatas ativos, que são "(...) criadores, fantasistas, que na coletividade espírita representam o papel de incubo”.

b) médiuns audientes ou mitopatas passivos, que seriam passivos também nas relações sexuais e também quanto à crença, aceitando tudo sem discernimento e sem postura crítica.

c) médiuns cenestopatas ou mitopatas ativo-passivo, que são oscilantes entre os dois anteriores, sendo um tipo intermediário.

Para ele, a maioria dos espíritas encontrar-se-ia na categoria intermediária. No caso de já doentes mentais com agravamento da loucura pelo espiritismo, determinava a causa da doença da seguinte maneira:

a) psicóticos maníaco-depressivos: espiritismo aparece como "causa acessória para a crise" (tanto quanto, por exemplo, os problemas conjugais).

b) os esquizofrênicos já apresentariam a doença antes de chegar aos centros espíritas e o espiritismo consistiria em um entre os delírios do doente, "perturbando seus órgãos sensoriais, agravando assim seu estado".

c) porém, existiria uma doença mental "causada pelo espiritismo num tarado nervoso”, ou seja, o espiritismo também causaria loucura em indivíduos com tendência ou com a doença em baixos graus, "que não se desenvolveriam caso o 'insano potencial' não tivesse contato com práticas ou doutrinas espíritas."

Para a doença que se enquadra neste último caso, estabelece etapas de evolução, seus estágios e sintomas: o primeiro seria a espiritolatria, em que o doente passa a procurar espíritos desencarnados; a segunda etapa seria a espiritofobia, que é o medo de espírito; e a última seria a espiritomania, que é o auge da doença, quando o indivíduo se vê "dominado pela força de uma sugestão insopitável”. As 
categorias mais recorrentes nas formulações médicas a respeito do espiritismo como fatores de alienação mental de maneira geral seriam: predisposição, sugestão, alucinação, delírio.

Outro médico que se destacou nos estudos acerca do espiritismo foi Antônio Austragésilo, professor da Faculdade de Medicina. Ele não escreveu obras sobre o assunto, porém, nos momentos em que foi chamado a falar sobre o espiritismo, associou os fenômenos mediúnicos a "crises histéricas", explicando-os por uma desarticulação entre o consciente e o subconsciente através do mecanismo da sugestão.

Leonídio Ribeiro afirmava que o espiritismo levava às perturbações mentais e atitudes criminosas. Sua postura diverge das ideias de O. Pimentel e de X. de Oliveira, ao classificar o baixo espiritismo como a prática mediúnica mais nociva. Entretanto, afirma que os diferentes espiritismos consistiriam em histeria contagiosa. Considerava a difusão do espiritismo como um "crime contra a saúde pública”. Adota preceitos evolucionistas ao afirmar que haveria uma predisposição hereditária de débeis psíquicos ao espiritismo. Neste sentido, os médiuns estariam num estágio primitivo, sendo comparados a crianças.

Para ele, o espiritismo provocava distúrbios mentais ou agravava doenças psíquicas já presentes nos indivíduos. L. Ribeiro propunha uma ação conjunta de médicos, policiais e jornalistas, a fim de combater o "mal social" que era 0 espiritismo. Os jornalistas deveriam se recusar a divulgar notícias sobre o espiritismo, enquanto a polícia fecharia os centros mais perigosos: os médiuns seriam enviados ao Hospício Nacional de Alienados para observação médica e, se após os exames de sanidade mental fossem considerados loucos, seriam internados; os outros, charlatães, seriam presos como elementos perigosos à sociedade.

A possessão aparece como fruto de autossugestão, e a levitação, aparições luminosas e materializações de fantasmas seriam resultado de hipnose. O que diferencia a postura de L. Ribeiro a dos demais, é que este não garante a inexistência de fenômenos sobrenaturais.

C. Gama afirma em sua dissertação que, para Leonídio Ribeiro, "o médium é (...) um mitomaníaco que, sem capacidade de perceber a "multiplicidade do eu', a interpreta como possessão espiritual”. E a comunicação com os mortos é vista por este médico como "lembranças latentes, complexos emotivos e recalques". 
Afirma que existem dois tipos de 'perturbações mentais' que se ligariam ao espiritismo:

a) o primeiro tipo seria causado pelo espiritismo em indivíduos predispostos, sujeitos à preocupação de ordem espírita (delírios espíritas polimorfos de débeis, delírios...)

b) já o segundo seriam perturbações mentais que se desencadeariam de qualquer maneira, sendo o espiritismo apenas um estopim que daria um colorido diferente, ocorrendo mais frequentemente em dementes precoces, psicoses maníaco-depressiva, psicoses tóxicas...

Também divide os espíritas em diversos tipos:

a) o primeiro tipo apresentaria predisposições hereditárias às afecções mentais, teria fé intensa e estável, seriam débeis psíquicos por acreditar nos delírios com espíritos, soluções para suas angústias;

b) predispostos, portadores de constituições acentuadamente esquizóides;

c) histéricos, maioria mulheres, que fariam exibições semelhantes às sonambúlicas;

d) psicóticos, em que se enquadram os loucos que delirariam com o espiritismo, ou seja, o espiritismo seria a forma plástica de expressão da loucura, e os que teriam o espiritismo como causa em si da loucura.

E. Giumbelli analisa o livro O espiritismo no Brasil: estudo clínico e médicolegal (1931) de L. Ribeiro e Murilo de Campos, professores da Faculdade de Medicina do Rio de Janeiro. M. de Campos trabalhou na década de 1920 como psiquiatra nos serviços de assistência a alienados e L. Ribeiro começou sua carreira, em 1917, como médico legista da polícia da cidade do Rio de Janeiro. É um estudo abrangente sobre o espiritismo, não só como fenômeno psiquiátrico, mas também sua realidade psicológica e sua composição sociológica.

Afirmam que o que os espíritas atribuem à intervenção de espíritos seria o produto de sugestões, dissociações psíquicas e afloramento do subconsciente. Para eles, tais fenômenos ocorrem em indivíduos já psicóticos que passam a incorporar "motivos espíritas" em seu quadro de sintomas. Eles começariam como uma simples impressão ou sugestão e evoluiria até tomar a forma de alucinações, desembocando em uma mania. O espiritismo seria uma forma moderna da magia, definida pelo apelo ao sobrenatural. Por consequência, várias práticas 
baseadas em rituais de mediunidade seriam espíritas - portanto, englobando de kardecistas a tradições africanas.

Neste livro, relatam mortes, suicídios e atentados ao pudor praticados durante ou em decorrência de práticas espíritas. Porém, Giumbelli afirma que o que mais irritava os médicos era o fato de a maioria dos espíritas serem curandeiros. Propunham uma campanha repressiva, através do impedimento de anúncios de centros espíritas em jornais, mobilização de autoridades policiais e sanitárias, fechamento de lugares de cultos mais perigosos, prendendo os responsáveis e entregando os médiuns à observação dos psiquiatras.

As temáticas do livro são divididas em:

a) explicação científica dos fenômenos ditos espíritas, sem recorrer à noção de espírito.

b) o espiritismo como fator de alienação mental. Afirmavam que deve haver uma predisposição para doenças mentais: "o espiritismo é perigoso exatamente porque pode ser o fator desencadeador da alienação mental”. Há a patologização do médium, não se limitando a este, pois também ameaçava a todos os frequentadores das práticas espíritas.

c) os danos que sua prática acarretaria à saúde mental. (GIUMBELLI, 1997-A, p. 52)

A partir da década de 1940, os médicos vão ser cada vez menos convidados a se pronunciar sobre o sentido e o efeito de práticas como a possessão e a mediunidade e, portanto, vão perdendo a legitimidade neste campo. Neste momento, ela continua atuante na dimensão corporativa, ou seja, em relação à garantia do exercício exclusivo da prática de cura.

Resumindo, em termos da luta dos médicos em relação aos espíritas no campo prático, podemos destacar alguns momentos e figuras importantes.

Em 1909, há conferências na Sociedade de Medicina e Cirurgia do Rio de Janeiro sobre os 'perigos do espiritismo', porém, após a discussão, o grupo decidiu que não havia necessidade de medidas para atacar o espiritismo.

Em 1927, o assunto é retomado sob o título de Problema Espiritismotendo como líder principal $\mathrm{L}$. Ribeiro que, em seu discurso antiespiritismo, afirma que $50 \%$ dos pacientes mentalmente doentes que avalia no departamento de medicina legal da polícia, tiveram inicialmente seus sintomas de loucura quando 
praticavam espiritismo. Após discussão, a sociedade aprovou que se criasse um comitê para analisar as providências para se interditar esta prática. As investigações científicas dos fatos pararam, mas foi feito um inquérito entre especialistas do assunto, resultando somente em diversas opiniões. O questionário é o seguinte:

a) Você pensa que os fenômenos espíritas têm base científica?

b) Vocês estão cientes dos fatos ou experiências do espiritismo científico?

c) A prática do espiritismo causa danos à saúde mental da pessoa?

d) A prática abusiva de tratamento de saúde pelos espíritas compromete a saúde pública?

A resposta consensual ao inquérito foi a de que o espiritismo é uma prática prejudicial que provoca psicopatologias nos predispostos.

Para C. Gama, "o saber médico não se constitui de maneira uniforme. Foram construídos diferentes saberes. A heterogeneidade (...) deve ser examinada a partir de diversos aspectos: posicionamentos políticos e acusações em relação ao espiritismo, cargos ocupados por esses médicos, o grau em que tecem críticas à doutrina em si, posturas que se assemelham a postura espírita e divergências internas ao campo médico." (GAMA, 1992, p. 244).

Agora analisaremos as atas encontradas na SMCJF que fazem referência ao espiritismo como causador de loucura e também atas que fazem menção a campanhas antiespíritas movidas por médicos em outras regiões do país.

Em 1907, observa-se, em meio a uma discussão acerca do suicídio e do aumento do número desses incidentes na cidade, referências diretas ao espiritismo. Eduardo de Menezes abre a discussão de 23/02/1907 - após passar a presidência ao Dr. Cristão Malta - falando sobre o grande número de suicídios que estava ocorrendo na cidade. Afirma que os suicídios seguem um padrão, sendo efetivados ou pela ingestão do ácido phénico ou pela precipitação no rio Paraibuna, principalmente na ponte Carlos Otto. O médico acredita que a multiplicidade dos meios demonstra que é resultado de imitação: "Trata-se, pois, de um mal collectivo, uma moléstia social, um mal social, cuja causa determinante é a imitação ou a suggestão, quaesquer que sejam as causas predisponentes individuais, isto é, a predisposição mórbida psychica dos pacientes." ${ }^{13}$

${ }^{13}$ Boletim da SMCJF, fev/1907. 
Como podemos observar, Eduardo de Menezes coloca o suicídio como um mal social, uma "moléstia social", que independeria da predisposição orgânica e psíquica do indivíduo para cometer o ato. Afirma, baseando-se em psychopatologistas e em tratadistas de medicina legal, que a imitação é o fator determinante das epidemias de suicídio e que as notícias da imprensa acerca destes episódios excitam a imitação, principalmente em indivíduos com "espíritos fracos e deprimidos por circunstâncias variáveis". Como medida profilática, sugere que se faça uma campanha para que os jornais não noticiem os casos de suicídio e muito menos os meios empregados para tal ato - campanhas nos moldes do que foi feita no Rio de Janeiro, através do médico Souza Lima. Nesta discussão, vários médicos da SMCJF colocam-se a favor desta campanha a nível local, dentre eles os Drs. Christovão Malta, Martinho da Rocha e Almada Rocha. Este último, aproveitando-se do assunto, coloca sua opinião sobre outros fatores que podem colocar-se como causa occasional ou determinante dos suicídios, os quais seriam sempre reveladores de "psychopathias transitórias". Esse médico destaca como outro fator para o suicídio, o "espiritismo, que sob todas as suas modalidades, [ilegível] a que se subordina à practica da medicina, onde empolgando as consciências e toda a actividade cerebral dos adeptos decididos, é capaz de determinar as formas delirantes systematizadas bem constituídas." ${ }^{14}$

Neste trecho percebemos que o médico generaliza as diversas práticas mediúnicas; e também o fato de que tais práticas levariam seus adeptos a ter sintomas delirantes. Afirma, com base em investigações feitas por ele mesmo e também em publicações alheias, que as formas mais comuns são a "romântica, a mystica, a dos perseguidos, sobre as quais dominam os delírios phobicos - a nosfobia nomeadamente". Coloca que o suicídio é um "epílogo de um desses dramas psychopathicos". Depois de sua exposição acerca do espiritismo, pergunta se não seria produtivo que a SMCJF e seus membros promovessem uma "propaganda moderada e decidida contra o alastramento de semelhantes practicas." Para ele, fazendo isso, estariam adotando uma espécie de "profilaxia social contra um mal que se generaliza" na cidade e que vem a contribuir com o aumento do número de suicídios. Tomando novamente a palavra Eduardo de Menezes, este diz que ao iniciar a discussão não tinha o objetivo de apontar as causas e origens do

${ }^{14}$ Boletim da SMCJF, fev/1907. 
suicídio. Afirma que se fossem analisar as causas não se poderia recriminar somente o espiritismo, já "que esta doutrina não approva, nem aceita o suicídio como uma solução justificável". Entretanto, concorda que o espiritismo pode levar ao suicídio aqueles indivíduos com espírito fraco e que se abalam com preocupações e tensões mentais com as quais não têm capacidade de resolver. Mas afirma que isso se dá no espiritismo, "pelo mesmo mecanismo outras ordens de preocupações e causas de tensão mental de espírito dá também logar ao estado anormal psychico que leva ao suicídio". Porém coloca que na cidade de Juiz de Fora não consta influência do espiritismo em caso algum de suicídio. Cita o caso do maestro Valle, o qual Eduardo de Menezes "conhecia particularmente as suas conviçcões espíritas e a frieza racional com que as nutria sem emoção". Afirma que o maestro tinha a obsessão do suicídio durante os períodos de "exarcerbações psycho-pathicas" e que ele atribuía a um espírito que o perseguia as alucinações auditivas e visuais. Para Eduardo de Menezes, isso seria um elemento secundário e, na verdade, o maestro era um "psychopata permanente sujeito a exacerbações mórbidas e aquelle estado mórbido revestia-se de todos os signaes característicos na ordem intelectual, moral e phisica ou somática, além de causas hereditárias provenientes de alguns de seus ascendentes." ${ }^{15}$

Nesta ata, percebemos que as ideias psiquiátricas sobre o espiritismo tiveram alcance na cidade e que havia médicos que apoiavam as mesmas, como é o caso de Almada Rocha, o qual inclusive afirma ter chegado à conclusão de que o espiritismo leva ao suicídio e à loucura através da leitura de teses, artigos e estudos sobre o assunto e também através de uma "investigação" que teria feito nos centros espíritas locais.

No final da sessão de 07/05/1924, o pediatra Villella Filho menciona notícias veiculadas no periódico Noitesobre o espiritismo, "parecendo-lhe que esses artigos são mais uma propaganda contra o espiritismo". Na opinião deste médico, o espiritismo seria uma das causas determinantes de moléstias e acha que a SMCJF deveria redigir ao redator do jornal uma moção de aplausos pela campanha que vem fazendo contra o espiritismo. Tal discussão foi encerrada neste dia e continuou na reunião seguinte, do dia 04/06/1924. Porém, o Dr. Villela

${ }^{15}$ Boletim da SMCJF, fev/1907. 
Filho declara que, tendo o jornal Noite acabado com as reportagens sobre o espiritismo, havia perdido a oportunidade da ideia que sugeriu na última sessão. ${ }^{16}$

O pesquisador C. Gama examina artigos publicados pela imprensa laica, em que há debates e acusações entre médicos e espíritas. Um desses jornais é 0 Noite, do Rio de Janeiro, em que observou somente denúncias, e não debates. O autor localiza as primeiras denúncias em meados da década de 1910, acusando o Centro Espírita Redentor, na cidade do Rio de Janeiro, de maltratos de pacientes em seu hospital, o qual seria clandestino, segundo os redatores deste jornal.

Na reunião de 10/11/1939, presidida por Carlos Teixeira, encontramos referências ao espiritismo nos debates dos médicos da SMCJF, quando o Dr. Olavo Lustosa comenta sobre uma campanha, que estava sendo realizada no Rio de Janeiro, contra "anúncios escandalosos", através de jornais e rádios. ${ }^{17}$ Este médico "lê alguns trechos de um trabalho do Dr. Pimentel referente ao mesmo assunto" e pede a colaboração da SMCJF nesta campanha. A proposta de Olavo Lustosa, após ter sido colocada em discussão, é aprovada e decidem enviar um ofício ao Dr. Pimentel e a Sílvio Pereira, dando apoio à campanha que está sendo feita no Rio de Janeiro. Em nenhum momento da ata, fala-se do espiritismo, porém concluímos que os "anúncios escandalosos" se referem a ele, porque a campanha é movida pelo Dr. Oscar Pimentel, que em 1939, fez uma campanha contra o espiritismo nos jornais do Rio de Janeiro.

Na ata da SMCJF, a campanha a que se referem são na verdade "acusações" aos espíritas no jornal Diário da Noite, liderada por Oscar Pimentel, a partir de outubro de 1939. O. Pimentel fala do espiritismo como "fruto da ignorância, charlatanismo e como prejudicial à saúde mental" (GAMA, 1992, p. 141). Também se refere ao espiritismo como um sinal de mentalidade primitiva, sendo práticas deprimentes desta superstição africanizada e de aldeia, segundo esse médico.

No ano de 1939, o médico Carlos Fernandes apresentou à SMCRJ um projeto visando reprimir o espiritismo. Tal projeto citava os artigos 156, 157 e 158 do Código Penal, e se referiam ao programa de rádio Hora Espírita

\footnotetext{
${ }^{16}$ Ata da SMCJF. maio-jun/1924.

${ }^{17}$ Ata da SMCJF, nov/1939.
} 
Radiofônica como divulgadores de uma doutrina nociva para a sociedade. Este médico envia o projeto ao ministro da Justiça, e pede a intervenção policial para garantir o cumprimento dos artigos do Código Penal, além de pedir ao Presidente da República para que se atentasse para a "nociva divulgação do espiritismo" (GAMA, p. 121).

Neste mesmo ano, através do periódico Diário da Noite, ocorreram desafios entre médicos e espíritas. O médico Carlos Fernandes, autor da moção apresentada à SMCRJ, é quem lança este desafio aos espíritas através do jornal, convidando-os a curar cegos e loucos. Os membros das associações espíritas se unem para responder a SMCRJ, defendendo o espiritismo a nível filosófico, doutrinário e científico. Um representante da Liga Espírita do Brasil, Lamonnier desafia Carlos Fernandes e afirma que este estava "debaixo de obsessão espiritual evidente". Esse mesmo espírita também responde a O. Pimentel sobre a cientificidade do espiritismo, que para ele seria "uma ciência e não desaparecerá (...). O espiritismo é Religião, Filosofia e Ciência”.

Encontramos, entre a documentação do fundo da SMCJF, uma ata que é dedicada a registrar o assunto de reuniões dedicadas à exposição oral através de palestras e conferências internas de seus sócios. Uma conferência que acreditamos ser importante foi do Dr. Guilherme de Souza, que, no dia 05/03/1943 versou acerca do tema "Progressos atuais da terapêutica neuro-psiquiátrica. Casos clínicos". ${ }^{18}$ Nesta conferência, o médico discorre sobre os métodos modernos de tratamento das moléstias mentais, como a radioterapia e a convulsioterapia e também sobre a esquizofrenia, a psicose maníaco depressiva, a sífilis cerebral, epilepsia e psicoses tóxicas. Entretanto, inicia sua fala denunciando o atraso e abandono do Brasil em relação a hospitais para indigentes, sendo o único que existe no país o Hospital do Juquery, em São Paulo. Também

lamenta a falta de propaganda adequada para generalização de preceitos de higiene mental. Critica o uso abusivo do álcool como elemento nefasto para o indivíduo e sua prole. O baixo espiritismo trabalhando e desagregando a sociedade, sob os olhos complacentes da polícia. Os gastos para profilaxia e cura da sífilis sobem de preço diariamente (...)

${ }^{18}$ Ata da SMCJF, mar/1943. 
Como observamos, o médico se refere ao espiritismo sob a forma de "baixo espiritismo", como um desagregador da sociedade no que se refere à saúde mental. Além disso, critica a ineficácia da polícia no que tange à repressão dessas práticas, as quais são criminalizadas no Código Penal de 1890.

\section{CONSIDERAÇÕES FINAIS}

Como vimos, as religiões mediúnicas se configuraram como objeto de estudos de médicos e psiquiatras no Brasil do século XX. Neste contexto, a SMCJF se colocou como uma instituição que se preocupava com a regulação do monopólio da profissão, o que é típico de uma corporação voltada para a união e defesa profissional. Além disso, mostramos como o tema do espiritismo estava presente nas discussões internas da corporação, colocado sempre como um problema, seja relacionado ao exercício ilegal da medicina ou como causador de alienação mental. Também observamos que os médicos da cidade estavam em sintonia com as discussões e campanhas movidas nos âmbito da capital federal e de outras instituições médicas do país, como é o caso da Sociedade de Medicina e Cirurgia do Rio de Janeiro.

\section{REFERÊNCIAS}

ALMEIDA, Angélica A. S. de; ALMEIDA, Alexander M de; LOTUFO NETO, Francisco. History of 'Spiritist madness' in Brazil. In: History of Psychiatry. n. 16 , v. 1, p. $05-25$.

CHRISTO, M. Europa dos Pobres: a belle-époque mineira. Juiz de Fora: EDUJUF, 1994.

GAMA, C. O Espírito da Medicina: médicos e espíritas em conflito. Dissertação. (Mestrado em Sociologia). UFRJ, 1992.

GIUMBELLI, E. O cuidado dosmortos uma história da condenação e legitimação do espiritismo. Rio de Janeiro: Arquivo Nacional, 1997. 
. Heresia, doença, crime ou religião: O espiritismo no discurso de médicos e cientistas sociais. Revista de Antropologia, vol. 40, $\mathrm{n}^{0} 2$ 2, 1997. (A) GUEDES, S. Umbanda e Loucura. VELHO, Gilberto (org.). Desvio e Divergência: uma crítica da patologia social. Rio de Janeiro: Zahar Editor, 1985. LANA, V. Sanear e Limpar. as propostas de intervencionismo da sociedade de Medicina e Cirurgia de Juiz de Fora (SMCJF) no espaço urbano juizforano. Anais do XXIII Encontro Nacional de História. Londrina, 2005.

MACHADO, U. Os intelectuais e o espiritismo - de Castro Alves a Machado de Assis. Uma reportagem sobre meio século (1860-1910) de difusão do espiritismo no Brasil, através das repercussões em nossos meios intelectuais e segundo o depoimento da literatura. Niterói: Publicações Lachâte, 1996.

OLIVEIRA, Xavier de. Espiritismo e loucura. contribuição ao estudo do fator religioso em psiquiatria.

PIRES, A. Café e indústria em Juiz de Fora: uma nota Introdutória. Mimeo. 1996.

ROXO, Henrique. Delírio Espírita dos Degenerados. In: Brasil-Médico, XL, v. 1, n. 19, 1926.

SCOTON, Roberta M. S. Espíritas enlouquecem ou espíritos curam?Uma análise das relações, conflitos, debates e diálogos entre médicos e kardecistas na primeira metade do século XX (Juiz de Fora - MG). Dissertação. (Mestrado em Ciência da Religião). UFJF, 2007. 